\title{
Colostomy in Anorectal Malformation and Hirschsprung's Disease in Infants and Children
}

\author{
Dr. Ali Laibi Zamil, \\ M.B. Ch.B, MRCS (Ireland), Surgical Department, \\ College of Medicine, Misan University, Misan, Iraq. \\ Dr. Osamah Abdul-Kadim Radhi, \\ M.B. Ch.B, F.I.C.M.S., Surgical Department, \\ Al-Sader Teaching Hospital, Misan, Iraq. \\ Dr. Helen Samer Hasan, \\ M.B. Ch.B, D.F.M., Primary Health Care center, Misan, Iraq.
}

Doi: 10.19044/esj.2018.v14n18p464 URL:http://dx.doi.org/10.19044/esj.2018.v14n18p464

\begin{abstract}
Background: There are numerous and frequent common complications following construction of large bowel stomas, which may lead to significant morbidity and mortality. The overall morbidity from colostomy has been reported to be as high as $42-75 \%$.

Aims of the study:

-To study the complications of colostomy (immediate, early \& late) taking into consideration the site and types of the colostomy.

-To determine the types and sites of colostomy in anorectal malformation and Hirschsprung's disease.

-To study some associated risk factors in colostomy with anorectal malformation and Hirschsprung's Disease.

-To estimate the rate of death for performed colostomies in anorectal malformation and Hirschsprung's disease.

Patients and methods: A cross-sectional prospective study included a total number of (160) temporary colostomies were performed for neonates, infants and children in the pediatric surgical department of Children Welfare Teaching Hospital in Baghdad over a period of three years from January 2008 to January 2011. A standardized data sheets were prepared for collecting the information including age, sex, associated congenital anomalies and colostomy data (type, site, indication, and complication). Results: Most of the colostomies were done in the neonatal period (69.4\%) and mainly for imperforate anus (46.9\%) while colostomies that were performed in infancy (26.2\%) were done mainly for Hirschsprung's disease (18.1\%). The most common type of stoma was right loop transverse colostomy for Hirschsprung's
\end{abstract}


disease (31.2\%) and pelvic loop for imperforate anus (42.5\%). 107 different complications developed in 71 patients as a result of colostomy formation and the most common complications were stomal prolapse, skin excoriation, wound sepsis, stomal stenosis, retraction, and bleeding. The mortality rate was 7.5\% (12 patients); 4 patients had Hirschsprung's disease and 8 patients had an imperforate anus. Conclusion: Hirschsprung's disease and imperforate anus were the most common indications of stoma formation in pediatric age group. The right transverse loop and pelvic loop colostomy were the commonest stoma that was performed with a high rate of complications.

Keywords: Colostomy, stoma, Hirschsprung, neonate

\section{Introduction}

A colostomy can be defined as surgical procedure made in the large colon to convert the pathway of feces and flatus to the exterior to be collected in an external appliance (Russell, 2004 \& Bastawrous, 1995). The history of colostomies date back to the late-eighteenth century, and some of the first survivors of colostomy were neonates with imperforate anus (O’Neil, 1998). The first surgeon who did a colostomy was Dubois in 1783 but unfortunately, the patient died after the procedure by 10 days. While a successful colostomy had been done by Duret (professor of surgery) in 1793 who did a colostomy in the neonate of 4 days old with anorectal malformation (O'Neil, 1998 \& Dinnick, 1934). The colostomy can be categorized into two types:

1. Temporary colostomy: in which a temporary procedure is performed as a part of the general management of mostly congenital malformations (Raffensporger, 1990 \& Cigdem, 2006).

2. Permanent colostomy: it is performed after excision of the rectum for a carcinoma (Raffensporger, 1990 \& Cigdem, 2006).

Anorectal malformations and Hirschsprung's disease are still to be considered as the most common indications for colostomy in newborns and infants (Raffensporger, 1990, Cigdem, 2006 \& Robber, 2005). Approximately, the prevalence rate of Hirschsprung's disease is 1/5000 live births (Suita, 1996) with nearly a similar rate in anorectal malformation 1/4000-5000 live births (Keith, 2005). The other indications for colostomy include; distal atresia of the colon, injuries in the colon and anorectal area, necrotizing enterocolitis, meconium ileus and high anal fistula (Raffensporger, 1990, O Neil, 2004 \& Pena, 2006).

There are frequent common complications occur after a procedure of colostomy which can cause significant morbidity and mortality. The overall morbidity from colostomy had been recorded to be 42-75\% (Brown, 2005 \& AL Salem, 1992). Complications after colostomy can be classified according to the time of occurrence into immediate or early and late complications. Early 
complications may include wound infection, abscess, fistula, necrosis, retraction, bleeding and obstruction of the small intestine (Russell, 2004, Fleshman, 2007 \& Lawrence, 1994).

Most of the immediate and early complications can be attributed to technical failures. Approximately $32-57 \%$ was reported as mechanical complications in Patwardhan et al study (Patwardhan, 2001). Finally, the late complications include a parastomal hernia, colostomy prolapse, stenosis, diarrhea and skin excoriation (Fleshman, 2007 \& Lawrence, 1994).

\section{Aims of the study}

- To study the complications of colostomy (immediate, early \& late) taking into consideration the site and types of the colostomy.

- To determine the types and sites of colostomy in anorectal malformation and Hirschsprung's disease.

- To study some associated risk factors in colostomy with anorectal malformation and Hirschsprung's Disease.

- To estimate the rate of death for performed colostomies in anorectal malformation and Hirschsprung's disease.

\section{Patients and methods}

A cross-sectional prospective study included total number of (160) temporary colostomies that were performed for neonates, infants and children in the pediatric surgical department of Children Welfare Teaching Hospital in Baghdad over a period of three years from January 2008 to January 2011. There were 70 patients with Hirschsprung's disease and 90 patients with anorectal malformations.

Data were collected from patients' records which include:

1.Age.

2.Sex.

3.Associated congenital anomalies.

4.Indications for colostomy.

5.The site of colostomy.

6. Type of colostomy.

7.Complications and management.

The analysis of data was carried out using the available statistical packages for social science, version 18.0(SPSS-18.0). Data were presented in form of a table of number and percentage. Chi-square test ( $\mathrm{x}^{\wedge} 2$-test) was used for testing the significance of the association between variable under study. Statistical significance was considered whenever the P-value was equal or less than 0.05 . 


\section{Results}

According to gender classification; totally males were forming 94 patients in which $40(42.5 \%)$ presented with anorectal malformations and 54(57.5\%) patients presented with Hirschsprung's disease. While females were 66 cases in which $50(75.8 \%)$ presented with anorectal malformations and $16(24.2 \%)$ patients with Hirschsprung's disease and these relationships were strongly significant as $\mathrm{p}$ is 0.0003 as shown in the table (1).

Table (1): Classification of stoma formation of colostomy in anorectal malformation and Hirschprung's disease according to the gender.

\begin{tabular}{|c|c|c|c|c|}
\hline Gender & $\begin{array}{c}\text { Anorectal malformations } \\
\text { Number (\%) }\end{array}$ & $\begin{array}{c}\text { Hirschsprung's disease } \\
\text { Number (\%) }\end{array}$ & Total & p \\
\hline Male & $40(42.5 \%)$ & $54(57.5 \%)$ & $94(100 \%)$ & \multirow{2}{*}{0.0003} \\
\hline $\begin{array}{c}\text { Female } \\
\begin{array}{c}\text { Male:Female } \\
\text { ratio }\end{array}\end{array}$ & $50(75.8 \%)$ & $16(24.2 \%)$ & $66(100 \%)$ & \\
\hline
\end{tabular}

The age of patients (at which the stoma of colostomy was performed) was ranging from 1 day to 9 years.

The sample was divided into 3 groups:

1. During the neonatal period: the total cases were $(69.4 \%)$ in which $(46.9 \%)$ patients presented with anorectal malformations and $(22.5 \%)$ patients presented with Hirschsprung's disease.

2. From 1-12 months: were forming $(26.2 \%)$ in which $(8.1 \%)$ presented with anorectal malformations and (18.1\%) presented with Hirschsprung's disease.

3. More than 1 year: were $(4.4 \%)$ in which $(1.3 \%)$ presented with anorectal malformations and $(3.1 \%)$ with Hirschsprung's disease.

The age (at which colostomy was performed) was significantly associated with anorectal malformations and Hirschsprung's disease; $\mathrm{p}$ is 0.0007 as shown in the table (2).

Table (2): Classification of stoma formation of colostomy in anorectal malformation and Hirschprung's disease according to the age.

\begin{tabular}{|c|c|c|c|c|}
\hline Age & $\begin{array}{c}\text { Anorectal malformations } \\
\text { Number (\%) }\end{array}$ & $\begin{array}{c}\text { Hirschsprung's disease } \\
\text { Number }(\boldsymbol{\%})\end{array}$ & Total & \multirow{2}{*}{0.0007} \\
\cline { 1 - 4 } $1-28$ days & $75(46.9 \%)$ & $36(22.5 \%)$ & $111(69.4 \%)$ & \\
\hline 1-12 months & $13(8.1 \%)$ & $29(18.1 \%)$ & $42(26.2 \%)$ & $7(4.4 \%)$ \\
\hline Over 1 year & $2(1.3 \%)$ & $5(3.1 \%)$ & $160(100 \%)$ & \\
\hline Total & $90(56.3 \%)$ & $70(43.7 \%)$ & \\
\hline
\end{tabular}

In anorectal malformation; loop and double barrel types pelvic colostomies were the main types which were applied in 68(75.6\%) and $18(20.0 \%)$ patients respectively. While only $5(7.2 \%)$ of Hirschsprung's disease had a double barrel type colostomy and this association was significant as $\mathrm{p}$ is 0.007 as shown in the table (3). 
The transverse colostomy was done mainly in Hirschsprung's disease in which a loop type colostomy was done in $50(71.4 \%)$ while a double barrel type colostomy was done in $15(21.4 \%)$ and this was not significant (p is 0.02). But when comparing these results totally; it was shown significant differences among not only for the indication of colostomy but also the type and site of colostomy ( $\mathrm{p}$ is 0.0001 ) as shown in the table (3). Regarding complication of colostomy: complications were shown in 107 patients and the most common complications were loop prolapsed, skin excoriation and wound infection in which they were forming 35 (32.7\%), 26 (24.3\%) and 13(12.2\%) respectively as shown in the table (4). There was a significant association between the type of colostomy and type of complication; in which $p$ are 0.007 and 0.002 for transverse and pelvic colostomy respectively. In addition, the total colostomies were significantly associated with the type of complication as $\mathrm{p}$ is 0.004 as shown in the table (4).

Table (4): Complications according to the type of colostomy.

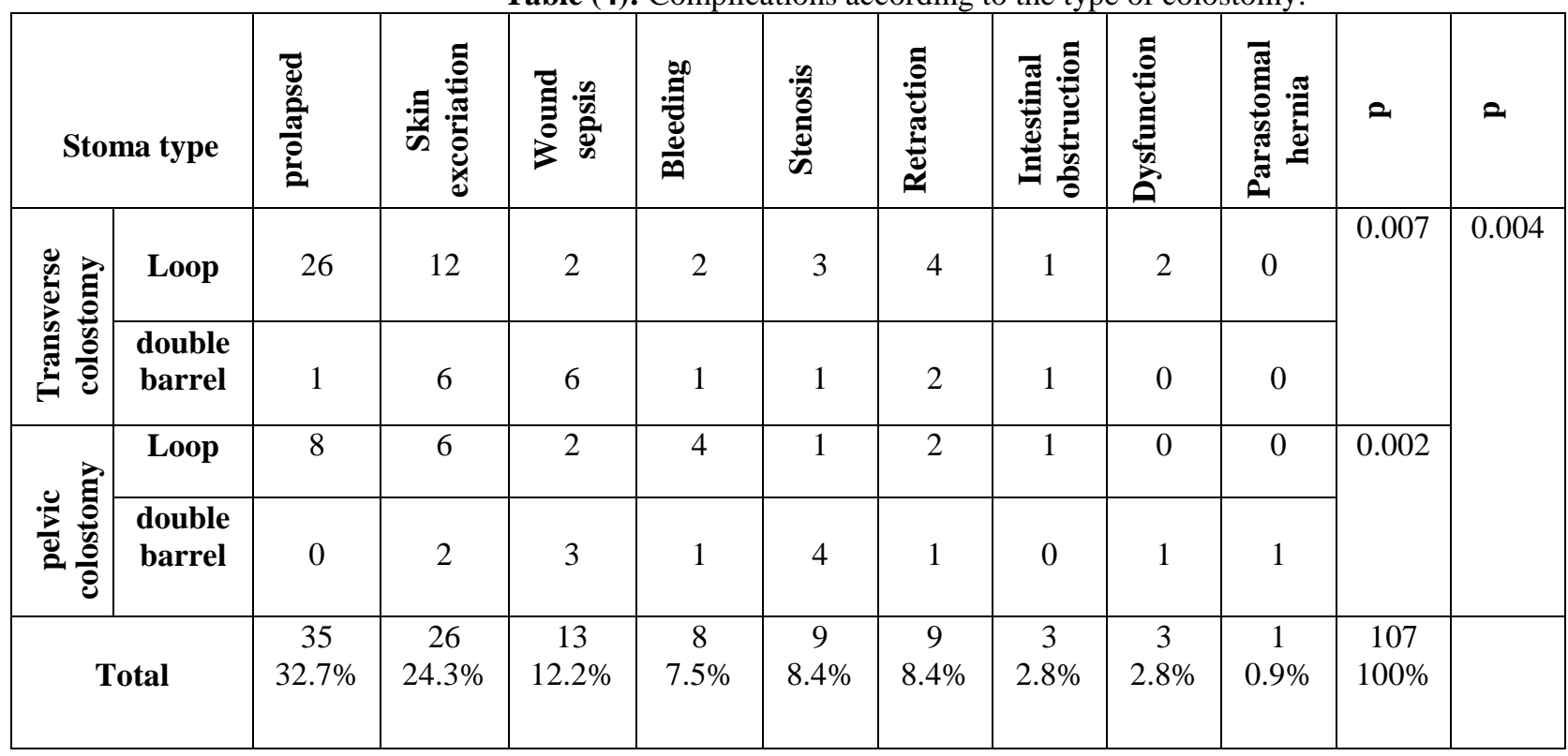

Distal loop prolapse occurred in 25 cases mainly of transverse type colostomies while only 2 cases in pelvic type. Proximal loop prolapse occurred in 5 colostomies (pelvic type) as shown in the table (5). 
Table (5): Site of loop prolapse in relation to the type of colostomy.

\begin{tabular}{|c|c|c|c|c|}
\hline \multicolumn{2}{|c|}{ Stoma type } & \multirow{2}{*}{$\begin{array}{c}\begin{array}{c}\text { Proximal loop } \\
\text { Number(\%) }\end{array} \\
0(0 \%)\end{array}$} & \multirow{2}{*}{$\begin{array}{c}\begin{array}{c}\text { Distal loop } \\
\text { Number(\%) }\end{array} \\
25(23.3 \%)\end{array}$} & \multirow{2}{*}{$\begin{array}{c}\begin{array}{c}\text { Both loops } \\
\text { Number }(\%)\end{array} \\
2(1.9 \%)\end{array}$} \\
\hline \multirow{2}{*}{$\begin{array}{l}\text { Transverse } \\
\text { colostomy }\end{array}$} & Loop & & & \\
\hline & Double barrel & $0(0 \%)$ & $0(0 \%)$ & $0(0 \%)$ \\
\hline \multirow{2}{*}{$\begin{array}{c}\text { Pelvic } \\
\text { colostomy }\end{array}$} & Loop & $5(4.7 \%)$ & $2(1.9 \%)$ & $1(0.9 \%)$ \\
\hline & Double barrel & $0(0 \%)$ & $0(0 \%)$ & $0(0 \%)$ \\
\hline \multicolumn{2}{|c|}{ Total } & $5(4.7 \%)$ & $27(25.2 \%)$ & $3(2.8 \%)$ \\
\hline
\end{tabular}

Wound infection had been occurred in 13(12.2\%) patients of performed colostomies which include; infection, abscess, dehiscence, and fistula and was $8(7.5 \%), 2(1.9 \%), 2(1.9 \%)$ and $1(0.9 \%)$ respectively as shown in the table (6).

Table (6): Types of wound sepsis in relation to the type of colostomy.

\begin{tabular}{|c|c|c|c|c|c|c|}
\hline \multicolumn{2}{|c|}{ Stoma type } & Infection & Abscess & Dehiscence & Fistula & \\
\hline \multirow{2}{*}{$\begin{array}{l}\text { Transverse } \\
\text { colostomy }\end{array}$} & Loop & $2(1.875 \%)$ & $0(0 \%)$ & $0(0 \%)$ & $0(0 \%)$ & \\
\hline & $\begin{array}{c}\text { Double } \\
\text { barrel }\end{array}$ & $2(1.875 \%)$ & $1(0.95 \%)$ & $2(1.9 \%)$ & $1(0.9 \%)$ & \\
\hline \multirow{2}{*}{$\begin{array}{c}\text { Pelvic } \\
\text { colostomy }\end{array}$} & Loop & $2(1.875 \%)$ & $0(0 \%)$ & $0(0 \%)$ & $0(0 \%)$ & \\
\hline & $\begin{array}{c}\text { Double } \\
\text { barrel }\end{array}$ & $2(1.875 \%)$ & $1(0.95 \%)$ & $0(0 \%)$ & $0(0 \%)$ & \\
\hline \multicolumn{2}{|c|}{ Total } & $8(7.5 \%)$ & $2(1.9 \%)$ & $2(1.9 \%)$ & $1(0.9 \%)$ & $13(12.2 \%)$ \\
\hline
\end{tabular}

Total number of death was $12(7.5 \%)$ patients only from total number (160 cases);

8 patients with anorectal malformations died because of associated congenital anomalies (congenital heart disease and tracheoesophageal fistula) forming 5 cases while the other ( 3 cases) died because of wound sepsis. While four died in patients with Hirschsprung's disease; three of them died due to late presentation of bowel perforation and the last case died due to sepsis as shown in the table (7).

Table (7): Mortality and causes of death in anorectal malformations and Hirschsprung's disease with a colostomy.

\begin{tabular}{|c|c|c|c|c|}
\hline $\begin{array}{c}\text { Disease } \\
\text { Number(\%) }\end{array}$ & Wound sepsis & $\begin{array}{c}\text { Associated } \\
\text { congenital anomalies }\end{array}$ & $\begin{array}{c}\text { Perforated } \\
\text { viscus }\end{array}$ & $\begin{array}{c}\text { Total } \\
\text { mortality }\end{array}$ \\
\hline $\begin{array}{c}\text { Anorectal } \\
\text { malformations } \\
90(56.3 \%)\end{array}$ & 3 & 5 & 0 & $8(5 \%)$ \\
\hline
\end{tabular}




\begin{tabular}{|c|c|c|c|c|}
\hline $\begin{array}{c}\text { Hirschsprung's } \\
\text { disease } \\
70(43.7 \%)\end{array}$ & 1 & 0 & 3 & $4(2.5 \%)$ \\
\hline $\begin{array}{c}\text { Total } \\
160(100 \%)\end{array}$ & $4(2.5 \%)$ & $5(3.1 \%)$ & $3(1.9 \%)$ & $12(7.5 \%)$ \\
\hline
\end{tabular}

\section{Discussion}

The temporary colostomy is an important surgical step in the initial management of a variety of diseases in neonates, infants, and children. The most common indications in the current study were Hirschsprung's disease and imperforate anus. Most of the stoma formations were performed in the neonatal period especially for imperforate anus while they were less in Hirschsprung's disease. Statistically, these results were strongly significant ( $p$ is 0.0007). Usually, the patient with an imperforate anus will be presented as an emergency with intestinal obstruction immediately after birth so urgent colostomy will be done. While in Hirschsprung's disease, some patients were responding to conservative treatment with rectal stimulation and irrigation then colostomy will be withheld.

The same was seen with Chandramouli et al study (Chandramouli, 2004); in which neonatal period was forming the major period for performing colostomies but the results were less in anorectal malformation and slightly more in Hirschsprung's disease. In anorectal malformation, male: female ratio was 1:1.25 which differ from those seen in other studies like Chandramouli et al study (2.7:1) (Chandramouli, 2004), Lister et al study (2.2:1) (Lister, 1983) and the same difference were seen with Hirschsprung's disease in which male: female ratio was 3.3:1, Chandramouli et al study (5:1) (Chandramouli, 2004) and Lister et al study (4.2:1) (Lister, 1983). Most of the surgeons in pediatric surgical department of Children Welfare Teaching Hospital were preferring to do right loop transverse colostomy; 50(71.4\%) in Hirschsprung's disease rather than pelvic colostomy $5(7.2 \%)$ to avoid creating a protective transverse colostomy during performing a definitive procedure, while in cases of imperforate anus, they were preferring to do loop type pelvic colostomy 68 (75.6\%) or double barrel type forming $(20 \%)$ and in pelvic colostomy, the complications are fewer. The indications of colostomy (regarding type and site) were similar to Chandramouli et al study (Chandramouli, 2004) in which there was a preference of transverse type colostomy in Hirschsprung's disease while preferring pelvic type colostomy in anorectal malformation. In addition, the current study revealed that there was a significant association between the indication of colostomy with the type and site of colostomy ( $p$ is 0.0001 ). The most common complication in this study was prolapsed colostomy which developed in 35 patients $(32.7 \%)$ and usually, it was occurring in right loop transverse colostomy (26 cases) while it was less frequent in double barrel colostomy (1 case only). 
Colostomy prolapse was more commonly affecting the distal limb $(25.2 \%)$ more than the proximal one $(4.7 \%)$ because the distal limb is dilated and hypertrophied especially in Hirschsprung's disease then with time it is decreasing in size and returning to the normal caliber that facilitates the prolapse. Also in a transverse colostomy, the distal limb represents a transverse colon which is redundant and liable for prolapse. The results of prolapsed colostomy in the current study were higher than Chandramouli et al $(18.9 \%)$ (Chandramouli, 2004), Lister et al study (12\%) (Lister, 1983) and Mollitt et al (11.6\%) (Mollitt, 1980). The second most common complication in this study was skin excoriation which occurred in 26 patients $(24.3 \%)$, it was high in comparison to Chandramouli et al (2\%) (Chandramouli, 2004) and approximately the same as Lister et al study (21.6\%) (Lister, 1983) and slightly less than Sheikh et al study (25\%) (Sheikh, 2006). In the current study; the reasons behind the high rate of skin excoriation were due to poor compliance of patients with colostomy appliance especially those from rural areas. In addition, there was a shortage in the supply of colostomy appliances in the hospital and it was expensive. Wound sepsis which include local wound infection, peristomal abscess (stitch abscess), dehiscence and fistula had occurred in 13 patients (12.2\%) which were forming high results in comparison with Chandramouli et al study (3\%) (Chandramouli, 2004) but lower than Lister et al study (17\%) (Lister, 1983).

Stomal stenosis occurred in 9 patients $(8.4 \%)$; the reasons of stenosis were due to the small opening that was created for colostomy and ischemia of margins of stoma which end with stenosis. 6 patients of them responding to dilatation under general anesthesia and 3 patients needed a revision of stoma. So stomal stenosis in this study was high if compared with many studies like Chandramouli et al study (1.4\%) (Chandramouli, 2004), Lister et al study (6.4\%) (Lister, 1983) and Mollitt et al study (6.2\%) (Mollitt, 1980). Stomal retraction had been occurred in 9 patients $(8.4 \%)$ and mostly in a transverse loop type colostomy (6 cases; 5.6\%). Revision of operation was done for 6 patients while 3 patients (divided type) are confined to the mucous fistula. A stomal retraction was high in comparison to Chandramouli et al study $(2.4 \%)$ (Chandramouli, 2004), Lister et al study (1.9\%) (Lister, 1983) and Mollitt et al study (3.4\%) (Mollitt, 1980). In addition, all retracted colostomy associated with skin problems. Bleeding occurred in 8 (7.5\%) of patients, it was higher in loop double type colostomy and usually was technical and it was high in comparison to Chandramouli et al (0.7\%) (Chandramouli, 2004) and Lister et al study (5\%) (Lister, 1983).

Intestinal obstruction occurred in 3 patients $(2.8 \%)$ and it was low in comparison with other studies like Chandramouli et al study (10\%) (Chandramouli, 2004) and Lister et al study (4\%) (Lister, 1983). One patient (Hirschsprung's disease with double barrel colostomy) had been explored and 
the adhesion around the wound was identified while the other 2 patients were treated conservatively. Three patients $(2.8 \%)$ had a stoma dysfunction (all the 3 patients had Hirschsprung's disease) which was higher than Chandramouli et al study (1\%) (Chandramouli, 2004). The stoma dysfunction usually occurs due to lack of leveling colostomy and frozen section. A parastomal hernia developed in 1 patient only $(0.9 \%)$ and usually occurred in a patient with poor abdominal wall muscle associated with local infection. Its incidence was approximately the same of Chandramouli et al study $(0.7 \%)$ (Chandramouli, 2004). In general, 107 patients forming 66.9\% (from total number of 160) developed different complications directly related to stoma formation that were much higher than Nour et al study in which complications occurred in $6.5 \%$ only (Nour, 1996), Hondle et al (23\%) (Hondle, 2014), Chandramouli et al reported $27.5 \%$ (Chandramouli, 2004), Lister et al (32\%) (Lister, 1983) and Mabula et al study (47.3\%) (Mabula, 2014).

The causes for this high rate of complication probably related to poor and bad care for colostomy and delayed closure of colostomy which is supported by a study of Chandramouli et al which concluded that proper stomal care, regular nutritional assessment, and early closure of the colostomy would minimize morbidity and mortality of colostomy and its closure (Chandramouli, 2004). Mortality rate was high in the current study reaching $7.5 \%$ (12 patients) in comparison to other studies like Nour et al study $(6.5 \%)$ (Nour, 1996), Mollit et al study (2.7\%) (Mollitt, 1980), Lister et al study (3.8\%) (Lister, 1983). Also, it was higher than Hondel et al study which showed that the mortality rate was $6 \%$ and none of them were directly related to stoma formation or closure (Hondle, 2014). This high mortality rate may be attributed to the absence of intensive care unit in Children Welfare Teaching Hospital and the lack of total parenteral nutrition.

The most common causes for death were associated with congenital anomalies (congenital heart disease, tracheoesophageal fistula, and associated Artesia), prematurity, intestinal obstruction, and wound sepsis. Revisions of stoma were done in $8.1 \%$ (13 patients) in this recent study and done for stomal stenosis, stomal dysfunction, intestinal obstruction and stomal retraction. This result is low in comparison to other studies like Mollit et al (16.4\%) (Mollitt, 1980), Lister et al (18.6\%) \%) (Lister, 1983) and Chandramouli et al (16.7\%) (Chandramouli, 2004).

\section{Conclusion}

Hirschsprung's disease and anorectal malformation were the most common indications for temporary colostomy in pediatric age group. Right loop transverse colostomy had the highest rate of complications while double barrel type was associated with less complication. Prolapse was the most common complication after right loop transverse colostomy and was more 
common in Hirschsprung's disease. It was the least to develop in double barrel colostomy. Mortality in the patient with anorectal malformation was usually associated with other associated congenital anomalies.

\section{Recommendations}

- Colostomy creation must be done by a well-trained surgeon.

- Right loop transverse colostomy should not be done routinely in Hirschsprung's disease and imperforate anus as it has a high rate of complications, double barrel instead of loop colostomy should be done.

- Double barrel descending colostomy is a procedure of choice for imperforate anus because of complete fecal diversion and low incidence of complications.

- Definitive surgery for Hirschsprung's disease and imperforate anus should be done as early as possible to reduce the length of time that child having a stoma.

- Single-stage repair for Hirschsprung's disease and imperforate anus must be the goal in the future.

\section{Acknowledgment:}

I would like to thank all the persons that they have great efforts to complete this research especially Dr. Esraa A. Ali (M.B.Ch.B/C.A.B.P) for revision and Dr. Hmoud M. Hassan (FICMS/ CM) for statistical work.

\section{Interest of Conflict:}

There is no interest of conflict with any organization and this research is not funded.

\section{References:}

1. AL Salem, A.H., Grant, C. S. (1992). Colostomy complications in infants and children. Int surg, 77, 164.

2. Bastawrous, A.A., Torosian, M.B., Statter, M.B., et al. (1995). Trends in pediatric ostomy surgery: intestinal diversion for necrotizing enter colitis and biliary diversion for biliary hypoplasia syndromes. J. Wound Ostomy Continence Nurs, 22(6), 280-283.

3. Brown, H., Randle, J. (2005). Living with a stoma: a review of the literature J Clin Nurs, 14 (1), 74-81.

4. Chandramouli, B., Srinivasan, K., Jagdish, S., Ananthakrishnan, N. (2004). Morbidity and mortality of colostomy and its closure in children. JPediatr Surg, 39(4),596-599.

5. Cigdem, M.K., Onen, A., Duran, H., Ozturk, H. and Otcu, S. (2006) The Mechanical Complications of Colostomy in Infants and children: 
Analysis of 473 Cases of a Single Center. Pediatric Surgery International, 22, 671-676.

6. Dinnick, T. The Origins and Evolution of Colostomy. (1934). British Journal of Surgery, 22, 142-154.

7. Fleshman, J.W., \& Lewis, M.G. (2007). Complications and Quality of Life after Stoma Surgery: A Review of 16,470 Patients in the UOA Data Registry. Seminars in Colon and RectalSurgery, 18, 19-24.

8. Hondel, D.V., Sloots, C., Meeussen, C., Wijnen, R. (2014). To split or not to split: colostomy complications for anorectal malformations or hirschsprung disease: a single center experience and a systematic review of the literature. Eur J Pediatr Surg,24(1),61-69.

9. Keith, W.A., George, W.H. (2005). Pedietric surgery. 4th edition. U.S.A. phildelphia: Elsevier suanders. 488.

10. Lawrence, W. (1994). Current surgical diagnosis and treatment. 10th edition. USA. California. Appleton and Lange. 689-690.

11. Lister, J. \& Smirza, P.J. (1983). Colostomy complications in children. Practitioner, 227-237.

12. Mabula, J.B., Kayange, N.M., Manyama, M., Chandika, A.B., Rambau, P.F., Chalya, P.L. (2014). Hirschsprung's disease in children: a five year experience at a university teaching hospital in northwestern Tanzania. BMC Res Notes, 28(7),410.

13. Mollitt,D.L., Malangoni, M.A., Ballantine, T.V., et al. (1980). Colostomy complications in children. An analysis of 146 cases. Arch surg, 115, 455-458.

14. Nour, S., Beck, J., and Stringer. (1996). Colostomy complication in infants and children. Annals of the Royal College of surgeon of England, 78(6), 526-530.

15. O Neil, J.A., Jay, L.G., Arnold, G.C. \& Anthong, A.C. (2004). Principles of pediatric surgery. 2nd edition. U.S.A.: Mosby. 597.

16. O’Neil, J.A., Micheal, Gauderer, W.L. (1998). Paediatric surgery. $5^{\text {th }}$ edition. USA. Mosby Year book Inc, 1349.

17. Patwardhan, N., Kiely, E.M., Drake, D.P., et al. (2001). Colostomy for anorectal anomalies: High incidence of complications. J Pediatr Surg, 36, 795-798.

18. Pena, A., Migotto-Krieger, M. \& Levitt, M.A. (2006) Colostomy in Anorectal Malformations: A Procedure with Serious but Preventable Complications. Journal of Pediatric Surgery, 41, 748-756.

19. Raffensporger, J.G. (1990). Swensen's pediatric snrgery. $5^{\text {th }}$ edition. Norwalk CT Appleton and Lang. 587-590. 
20. Robber, M., Aresman \& Daniel A. (2005). Bambini and Stephe Almond pediatric surgery. 2nd edition. U.S.A: Landes Bioscience. 370.

21. Russell, R.C.G., Williams, N.S. \& Bulstrode C.J.K. (2004). Baily and Love's short practice of surgery. $24^{\text {th }}$ edition. London Arnold, 11821185.

22. Sheikh, M.A., Akhtar, J., Ahmed, S. (2006).Complications and problems of colostomy in infant and children. JCPSP, 16(8), 509-513.

23. Suita, S., Taguchi, T., Kamimura, T., et al. (1996). A changing profile of Hirschsprung's disease in Japan - result from a national wide survey. J Jap Soc Pediatr Surg, 32, 952-65. 